\title{
PENGARUH KOMPENSASI DAN MOTIVASI KERJA TERHADAP KINERJA KARYAWAN \\ (Studi Kasus di PT. Lautan Otsuka Chemical)
}

\author{
Heri Murtiyoko ${ }^{1)}$
}

1) dosen universitas pamulang, email : dosen01036@unpam.ac.id

\section{ARTICLES

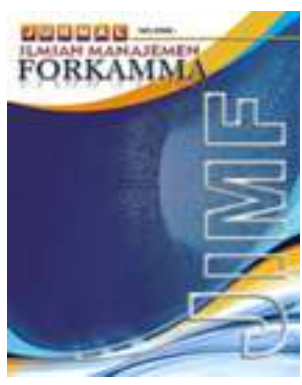

JURNAL ILMIAH MANAJEMEN FORKAMMA

Vol.2, No.1, November 2018 Halaman : $105-116$

C) LPPM \& FORKAMMA

Prodi Magister Manajemen

UNVERSITAS PAMULANG

ISSN (online) : 2599-171X

ISSN (print) : : 2598-9545

\section{Keyword :}

Kompensasi, Motivasi Kerja, Kinerja Karyawan

JEL. classification :

C33, G20, G23, N65

\section{Contact Author :}

\section{PRODI}

\section{MAGISTER MANAJEMEN \&} FORKAMMA UNPAM

JL.Surya Kencana No.1 Pamulang

Tangerang Selatan - Banten

Telp. (021) 7412566, Fax (021) 7412491

Email :

jurnalforkamma.unpam@gmail.com
Tujuan penelitian ini untuk mengetahui seberapa besar pengaruh kompensasi dan motivasi kerja terhadap kinerja karyawan pada PT. Lautan Otsuka Chemical, Jakarta. Jenis penelitian merupakan penelitian kuantitatif dianalisis menggunakan statistik. Adapun jumlah sampel yang digunakan sebanyak 154 responden. Analisis data menggunakan SPSS Versi 19. Teknik uji sampling menggunakan metode random sampling dan teknik pengambilan data diantaranya uji validitas, uji reliabilitas, uji asumsi klasik dan uji regresi linear berganda serta uji hipotesis. Hasil penelitian menunjukan bahwa kompensasi memiliki pengaruh sebesar $16,8 \%$ terhadap kinerja karyawan dan motivasi kerja memiliki pengaruh sebesar $3,2 \%$ sedang pengaruh secara simultan kompensasi dan motivasi kerja terhadap kinerja karyawan sebesar $16,8 \%$

The purpose of this study was to determine how much influence compensation and work motivation on employee performance at PT. Lautan Otsuka Chemical, Jakarta. This type of research is quantitative research analyzed using statistics. The number of samples used was 154 respondents. Data analysis using SPSS Version 19. The sampling test technique uses random sampling method and data retrieval techniques including validity test, reliability test, classic assumption test and multiple linear regression test and hypothesis test. The results showed that compensation had an effect of $16.8 \%$ on employee performance and work motivation had an influence of $3.2 \%$ while the influence of simultaneous compensation and work motivation on employee performance was $16.8 \%$ 


\section{A. Pendahuluan}

Dalam suatu perusahaan, sumber daya manusia merupakan aset perusahaan yang sangat penting dan berguna bagi kepentingan manajemen dalam menjalankan aktivitas perusahaan. Karyawan sebagai sumber daya manusia harus diperhatikan dengan sungguh-sungguh. Kedudukan sumber daya manusia saat ini bukan hanya sebagai alat produksi tetapi juga sebagai penggerak dan penentu berlangsungnya proses produksi dan segala aktivitas organisasi. Karyawan atau pegawai merupakan unsur terpenting dalam menentukan maju mundurnya suatu perusahaan. Menurut Dauglas dalam Faustino Cardoso Gomes (2003:90), menjelaskan bahwa perusahaan membutuhkan karyawan yang mampu bekerja lebih baik dan lebih cepat, sehingga diperlukan karyawan yang mempunyai kinerja (job performance) yang tinggi. Tetapi dalam kenyataannya dimana penulis melakukan penelitian dalam tiga tahun terakhir didapatkan bahwa target produksi tidak terpenuhi, terjadi peningkatan ketidakpatuhan karyawan terhadap aturan kerja yang telah disepakati bersama, serta pekerjaan yang tidak dapat terselesaikan sesuai dengan waktu yang ditentukan.

Dalam hal kompensasi untuk menjamin tercapainya keselarasan tujuan, pimpinan organisasi bisa memberikan perhatian dengan memberikan kompensasi yang layak, karena kompensasi merupakan bagian dari hubungan timbal balik antara organisasi dengan sumber daya manusia. Kompensasi adalah penghargaan atau ganjaran pada para pekerja yang telah memberikan kontribusi dalam mewujudkan tujuannya, melalui kegiatan yang disebut bekerja. Masalah-masalah yang didapatkan yaitu lingkungan kerja yang kurang mendukung seperti ketidak nyamanan dalam bertugas yang salah satunya disebabkan kurang arifnya atasan dalam memberikan teguran apabila bawahan melakukan kesalahan, minimnya pujian yang diberikan atasan apabila karyawan berhasil dengan baik dalam menyelesaikan suatu tugas pekerjaan, serta kenaikan gaji yang belum sepenuhnya sesuai dengan Perjanjian Kerja Bersama dibagian kurangnya perhatian perusahaan dalam mempertimbangkan faktor kemampuan perusahaan.

Tidak hanya faktor pemberian kompensasi saja yang perlu diperhatikan oleh perusahaan guna meningkatkan kinerja karyawan, akan tetapi perusahaan harus memperhatikan faktor motivasi. Setiap pegawai belum tentu bersedia mengerahkan prestasi kerja yang dimilikinya secara optimal, sehingga masih diperlukan adanya pendorong agar seseorang mau menggunakan seluruh potensinya untuk bekerja. Daya dorong tersebut disebut dengan motivasi. Sementara permasalah yang didapatkan adalah masih didapatkan kurangnya sarana dalam bekerja seperti kendaraan operasional, perusahaan sering menyampaikan kepada karyawan tentang kondisi perusahaan secara umum yang kurang stabil dalam berbagai kesempatan. Hal ini tentunya akan berdampak pada kemampuan dan kemauan bekerja dari pekerja.Menurut Philip Kotler dan Kevin Lane Keller yang dikutip dari buku Manajemen Pemasaran mengatakan bahwa Kepuasan Konsumen adalah perasaan senang atau kecewa seseorang yang muncul setelah membandingkan kinerja (hasil) produk yang dipikirkan terhadap kinerja yang diharapkan (2007:177).

Berdasarkan uraian di atas, maka penulis tertarik mengambil judul: "Pengaruh Kompensasi dan Motivasi Kerja terhadap Kinerja Karyawan pada PT. Lautan Otsuka Chemical - Jakarta".

\section{B. Perumusan Masalah}

Berdasarkan latar belakang yang telah diungkapkan di atas, maka rumusan masalah dalam penelitian ini adalah :

1. Seberapa besar pengaruh kompensasi terhadap kinerja karyawan?

2. Seberapa besar pengaruh motivasi kerja terhadap kinerja karyawan?

3. Seberapa besar pengaruh kompensasi dan motivasi kerja terhadap kinerja karyawan secara simultan? 


\section{Kerangka Berpikir}

Kerangka berfikir penelitian ini dapat digambarkan sebagai berikut:

\section{PENGARUH KOMPENSASI DAN MOTIVASI KERJA TERHADAP KINERJA KARYAWAN PADA PT. LAUTAN OTSUKA CHEMICAL - JAKARTA}

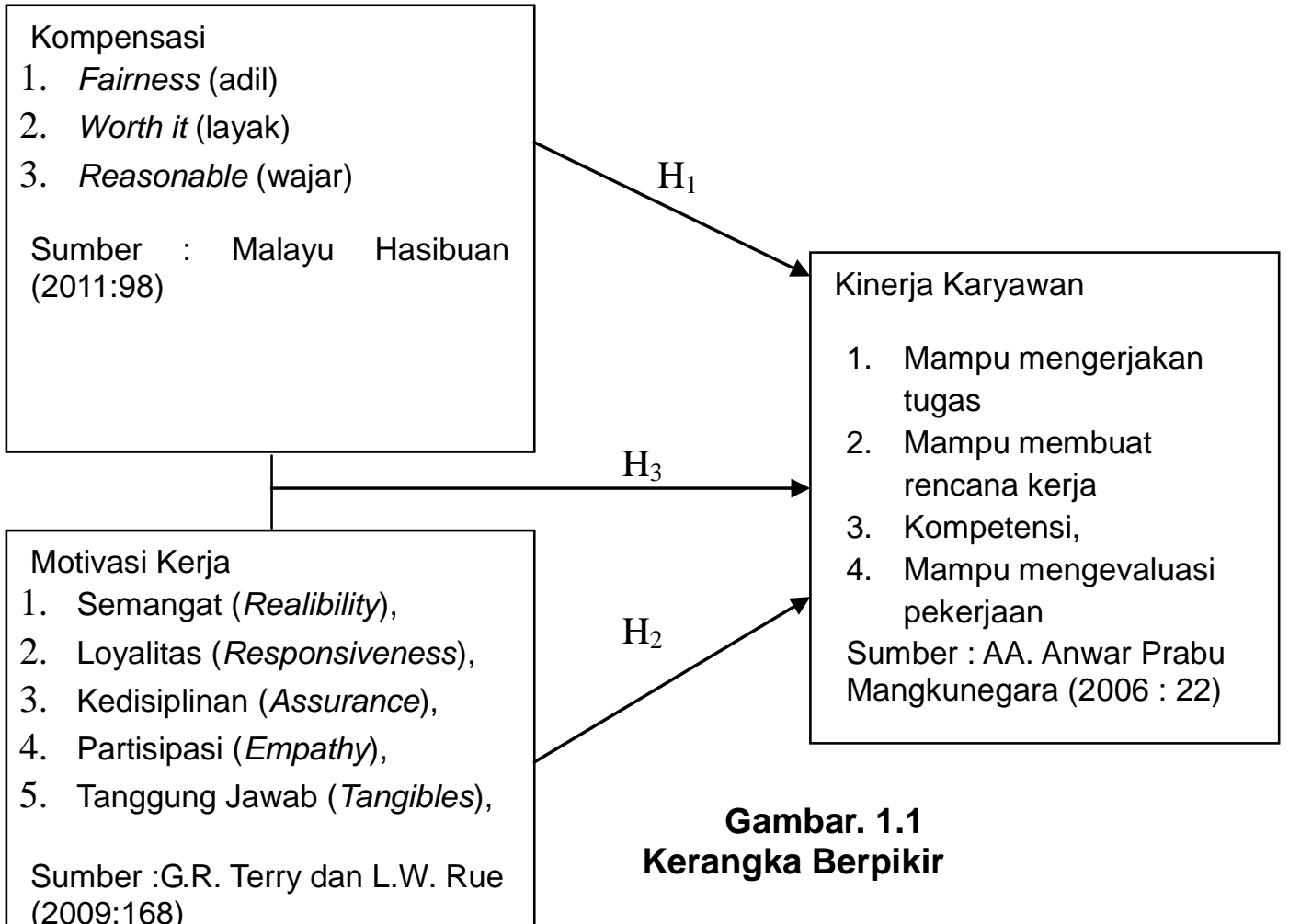

\section{Landasan Teori}

\section{Kompensasi}

Menurut Sedarmayanti (2011:262) kompensasi adalah segala sesuatu yang diterima karyawan sebagai balas jasa mereka. Menurut Werher dan Davis dalam Wibowo (2012:348), mendefinisikan kompensasi adalah sebagai apa yang diterima pekerja sebagai takaran atas kontribusinya kepada organisasi. Gary Dessler (1997:85) menyatakan, kompensasi karyawan adalah setiap bentuk pembayaran atau imbalan yang diberikan kepada karyawan dan timbul dari dipekerjakannya karyawan itu.

Menurut Malayu S.P. Hasibuan (2011:98) azas kompensasi adalah sebagai berikut

1) Azas Adil

Besarnya kompensasi yang dibayar kepada setiap karyawan harus disesuaikan dengan prestasi kerja, jenis pekerjaan, risiko pekerjaan, tanggung jawab, jabatan pekerja. Dengan azas adil akan tercipta suasana kerjasama yang baik. Semangat kerja, disiplin, loyalitas, dan stabilitas karyawan yang akan lebih baik.

2) Azas layak dan wajar

Kompensasi yang diterima karyawan dapat memenuhi kebutuhannya pada tingkat normatif yang ideal. Tolak ukur layak adalah relatif, penetapan besarnya kompensasi 
didasarkan atas batas upah minimal pemerintah dan eksternal konsistensi yang berlaku.

\section{Motivasi Kerja}

Menurut Malayu S.P. Hasibuan (2009:216) motivasi berasal dari bahasa Latin, Mavere yang berarti dorongan atau daya penggerak. Mc. Donald dalam Martinis Yamin (2007:54) mendefinisikan motivasi adalah perubahan energi dalam diri (pribadi) seseorang yang ditandai dengan timbulnya perasaan dan reaksi untuk mencapai tujuan. G.R Terry dan L.W Rue (2009:168) motivasi juga dapat didefinisikan sebagai membuat seseorang menyelesaikan pekerjaan dengan semangat, karena orang itu ingin melakukannya.

Dari uraian diatas dapat dikatakan bahwa motivasi kerja adalah segala dorongan baik dari dalam maupun luar diri seseorang / karyawan untuk melaksanakan tugas dan tanggung jawab dilingkungan pekerjaannya dengan segala kemampuan dan ketrampilan yang dimilikinya.

\section{a. Tujuan Pemberian Motivasi Kerja}

1. Mendorong gairah dan semangat kerja

2. Meningkatkan moral dan kepuasan kerja

3. Meningkatkan produktifitas kerja

4. Mempertahankan loyalitas dan kestabilan kerja

5. Meningkatkan kedisiplinan dan menurunkan tingkat absensi karyawan

6. Menciptakan hubungan dan suasana kerja yang baik

7. Mengefektifkan pengadaan karyawan

8. Meningkatkan kreatifitas dan partisipasi

9. Meningkatkan tingkat kesejahteraan karyawan

10. Mempertinggi rasa tanggung jawab karyawan terhadap tugas-tugasnya

11. Meningkatkan efisiensi penggunaan alat-alat dan bahan baku.

\section{Kinerja Karyawan}

Kinerja SDM merupakan istilah yang berasal dari kata job performance yang berarti prestasi kerja. Menurut Bambang Kusriyanto dalam A.A. Anwar Prabu Mangkunegara (2006:9), definisi kinerja karyawan adalah perbandingan hasil yang dicapai dengan peran serta tenaga kerja persatuan waktu. Kinerja mempunyai makna yang lebih luas, bukan hanya hasil kerja, tetapi termasuk bagaimana proses pekerjaan berlangsung. Kinerja merupakan hasil pekerjaan yang mempunyai hubungan kuat dengan tujuan strategis organisasi, kepuasan konsumen, dan memberikan kontribusi pada ekonomi.

Menurut pendapat Amstrong dan Baron dalam Wibowo (2012:7) kinerja adalah tentang melakukan pekerjaan dan hasil yang dicapai dari pekerjaan tersebut. Kinerja dapat dikatakan pula tentang apa yang dikerjakan dan bagaimana cara mengerjakannya.

Menurut Malayu S.P. Hasibuan (2011:34), pengertian kinerja adalah suatu hasil kerja yang dicapai seseorang dalam melaksanakan tugas-tugas yang dibebankan kepadanya yang didasarkan atas kecakapan, pengalaman dan kesungguhan serta waktu.

\section{E. Metodologi Penelitian}

Jenis penelitian merupakan penelitian kuantitatif karena data penelitian berupa angka-angka yang nantinya akan dianalisis menggunakan statistik Penelitian ini bertujuan untuk mengetahui pengaruh kompensasi dan motivasi kerja terhadap kinerja karyawan di PT. Lautan Otsuka Chemical - Jakarta.

\section{Populasi Dan Sampel}

a) Populasi

Menurut sugiyono (2013:80) adalah wilayah generalisasi yang terdiri atas objeck atau subjekyang mempunyai kualitas dan karakteristik tertenru yang ditetapkan 
peneliti untuk di pelajari kemudian ditarik kesimpulanya. Yang menjadi populasi dalam penelitian ini adalah karyawan yang bekerja di PT. Lautan Otsuka Chemical. Dalam penelitian ini tidak seluruh populasi yang diambil, oleh karena itu dalam penelitian ini digunakan sampel, yaitu sebagian dari jumlah dan karakteristik yang dimiliki oleh populasi tersebut

b) Sampel

Sampel adalah bagian dari jumlah karakteristik yang dimiliki oleh populasi, sampel diambil dengan menggunakan probabylity sampling (Sugiono, 2009:62) Teknik dalam pengambilan sampel ini ialah Random Sampling yaitu teknik pengambilan sempel dimana semua individu dalam populasi baik secara sendiri-sendiri atau bersama-sama diberi kesempatan yang sama untuk dipilih sebagai anggota sempel (Sugiyono, 2003:74) sesuai dengan namanya maka sampel yang diambil dilakukan secara acak. Untuk menentukan jumlah sampel yang dibutuhkan dalam penelitian ini ditentukan dengan rumus Slovin, yaitu :

$$
\begin{aligned}
& n=\frac{N}{1+N e^{2}} \\
& n=\frac{250}{1+250(0.05)^{2}} \\
& n=153,8=>\text { dibulatkan menjadi } 154 \\
& \mathrm{~N} \quad=\text { Populasi } \\
& \mathrm{e} \quad=\text { Tingkat keyakinan yang dibutuhkan dalam penelitian (95\%) } \\
& \text { moe } \quad=\text { margin off erorr (kesalahan maximum yang bisa ditolerir } \\
& \text { sebesar } 5 \% \text { ) }
\end{aligned}
$$

\section{Analisis Data}

Analisis data Analisis data yang digunakan dalam penelitian ini adalah uji validitas dan uji reliabilitas. Pengujian validitas menggunakan rumus korelasi pearson product moment, dengan ketentuan jika hiung $r>$ tabel $r$, berarti instrumen valid. Pengujian reliabilitas dalam penelitian ini menggunakan nilai Alpha Coanbach dengan ketentuan jika Alpha Croanbach ( hitung $r$ ) $>0,60$ berarti instrumen tersebut reliabel. Teknik analisis data antara lain uji asumsi klasik dan analisis regresi ganda. Uji asumsi klasik terdiri dari uji normalitas, uji multikolinearitas, uji heteroskedastisitas, uji autokorelasi.

\section{Uji Normalitas}

Data yang telah terkumpul harus diuji normalitasnya terlebih dahulu guna mengetahui apakah data penelitian berasal dari populasi yang sebarannya normal atau tidak. Pengujian normalitas menggunakan One-sample Kolmogorov-Smirnov Test dengan SPSS 19.0 for windows. Dengan ketentuan, jika nilai Asymp Sig > 0,05 maka data berdistribusi normal.

\section{Uji Multikolinearitas}

Uji Multikolinearitas dilakukan untuk mengetahui ada tidaknya kemiripan yang dimiliki oleh satu variabel independent dengan variabel independen yang lain dalam satu model. Pengujian multikolinearitas dalam penelitian ini menngunakan VIF (Variance Inflation Factor), dengan ketentuan jika nilai tolerance $>0,1$ dan nilai VIF $<10$, maka data tidak maka data tidak mengalami multikolinearitas.

\section{Uji Heterokedastisitas}

Pengujian dilakukan untuk mengetahui apakah terjadi penyimpangan model karena 
gangguan variabel yang berbeda antar observasi ke observasi lain. Untuk mengetahui apakah terjadi heteroskedastisitas atau tidak, dapat dilihat pada gambar Scattreplot, jika pada gambar scatterplot tidak ada pola yang jelas serta titiktitik menyebar diatas dan dibawah angka 0 pada sumbu Y, maka tidak terjadi heterokedastisistas.

\section{Analisis Regresi Ganda}

Teknik analisis regresi ganda dipergunakan untuk mengetahui pengaruh kualitas produk dan kualitas pelayanan terhadap kepuasan pelanggan CV. Usaha Mandiri. Dengan persamaan regresi $Y=a+b_{1} X_{1}+X_{2} b_{2}+X_{3} b_{3}$.

Teknik pengujian hipotesis menggunakan uji parsial dan uji simultan dengan teknik probabilitas, dengan cara membandingkan nilai probabilitas Sig dengan taraf signifikansi 0,05 . Jika nilai probabilitas sig $<0,05$ maka signifikan.

\section{Koefisien Determinasi}

Pengujian koefisien determinasi bertujuan untuk mengetahui besarnya pengaruh antar variabel. Nilai koefisien determinasi menunjukkan presentase variasi nilai variabel dependen yang dapat dijelaskan oleh persamaan regresi yang dihasilkan.

\section{F. Hasil Analisis Data dan Hasil Penelitian}

\section{Uji Validitas dan Uji Reliabilitas}

Hasil uji validitas dengan menggunakn rumus korelasi product moment dan membandingkan dengan $r$ tabel dengan taraf siginfikansi sebsar $5 \%$ maka diperoleh $r$ tabel yaitu 0,198 sehingga berikut ini hasil intrumen kusiner no 1 untuk setiap variabel diperoleh nilai:

a. Kompensasi, instrument kuisioner no 1 diperoleh nilai $r_{\text {hitung }}(0,473)>$ tabel $(0,361)$ sehingga instrument no 1 dikatakan valid.

b. Motivasi Kerja instrument kuisioner no 1 diperoleh nilai $r{ }_{\text {hitung }}(0,497)>r_{\text {tabel }}$ $(0,361)$ sehingga instrument no 1 dikatakan valid.

c. Kinerja instrument kuisioner no 1 diperoleh nilai $r$ hitung $(0,693)>r_{\text {tabel }}(0,361)$ sehingga instrument no 1 dikatakan valid.

Setelah dilaukan uji validitas dan seluruh intrumen di nyatakan valid, maka tahap selanjut nya adlaah uji reliabilitas dimana $r$ ca di bandingkan dengan $r$ tabel pada setiap variabel kuisioner nya:

a. Kompensasi, memperoleh nilai alpha croncbahc ca $(0,931)>$ tabel $(0,361)$ sehingga kuesioner variabel kompensasi dikatakan reliabel.

b. Motivasi Kerja, memperoleh nilai $r_{\text {ca }}(0,859)>$ tabel $(0,361)$ sehingga kusioner variabel motivasi kerja dikatakan reliabel

c. Kinerja, memperoleh nilai $r_{\text {ca }}(0,875>$ tabel $(0,361)$ sehingga kusioner variabel kinerja dikatakan reliabel.

\section{Uji Asumsi Klasik}

\section{Uji Multikolinearitas}

Pengujian ada tidaknya gejala multikolinieritas dilakukan dengan mempertahankan nilai matriks korelasi yang dihasilkan pada saat pengolahan data serta nilai VIF (Variance Inflation Factor) dan tolerance sebagai berikut: 
Tabel. 1.1 Uji Multikolinearitas

\begin{tabular}{|c|c|c|c|c|c|}
\hline & \multicolumn{2}{|c|}{ Coefficients $^{a}$} & & & \\
\hline \multirow[b]{2}{*}{ Model } & $\begin{array}{l}\text { Standardized } \\
\text { Coefficients }\end{array}$ & \multirow[b]{2}{*}{$\mathrm{t}$} & \multirow[b]{2}{*}{ Sig. } & \multicolumn{2}{|c|}{ Collinearity Statistics } \\
\hline & Beta & & & Tolerance & VIF \\
\hline 1 (Constant) & & 6.604 & .000 & & \\
\hline KOMPENSASI & .402 & 4.978 & .000 & .843 & 1.187 \\
\hline MOTIVASI & .019 & .235 & .814 & .843 & 1.187 \\
\hline
\end{tabular}

\section{Sumber: Hasil Olah Data Penelitian}

Berdasarkan tabel diatas maka diperoleh nilai tolerance value variabel Kompensasi $0,843>0,10$ dan sedangkan VIF nya $1,187<10,00$ lalu nilai tolerance value variabel Motivasi diperoleh nilai $0,843>0,10$ sedangkan VIF nya diperoleh nilai $1,187>0,10$ sehingga data tersebut tidak terjadi multikolinearitas.

\section{Uji Normalitas}

Uji Normalitas bertujuan menguji apakah model regresi, variabel dependen dan independen keduanya memiliki distribusi normal atau tidak. Uji normalitas dapat dilihat dari nilia Asym.sig pata tabel One Sample Kolmogrov Smirnov Test:

Tabel 1.2 Uji Normalitas

One-Sample Kolmogorov-Smirnov Test

\begin{tabular}{|c|c|c|}
\hline & & $\begin{array}{c}\text { Unstandardized } \\
\text { Residual }\end{array}$ \\
\hline $\mathrm{N}$ & & 154 \\
\hline \multirow[t]{2}{*}{ Normal Parameters ${ }^{a, b}$} & Mean & .0000000 \\
\hline & Std. Deviation & 6.00907180 \\
\hline \multirow[t]{3}{*}{ Most Extreme Differences } & Absolute & .087 \\
\hline & Positive & .061 \\
\hline & Negative & -.087 \\
\hline Kolmogorov-Smirnov Z & & 1.080 \\
\hline Asymp. Sig. (2-tailed) & & .194 \\
\hline
\end{tabular}

a. Test distribution is Normal.

b. Calculated from data.

\section{Sumber: Hasil Olah Data Penelitian}

Dari tabel diatas maka diperoleh nilai Asym Sig 2 tailed 0,194 $>0,05$ sehingga data tersebut berdistribusi normal. 


\section{Analisi Regresi Linear Berganda}

Tabel 1.3 Analisis Regresi Linier Berganda

\begin{tabular}{|c|c|c|c|c|c|c|}
\hline \multicolumn{7}{|c|}{ Coefficients $^{a}$} \\
\hline \multirow{2}{*}{\multicolumn{2}{|c|}{ Model }} & \multicolumn{2}{|c|}{ Unstandardized Coefficients } & \multirow{2}{*}{$\begin{array}{c}\text { Standardized } \\
\text { Coefficients } \\
\text { Beta } \\
\end{array}$} & \multirow[b]{2}{*}{$\mathrm{t}$} & \multirow[b]{2}{*}{ Sig. } \\
\hline & & B & Std. Error & & & \\
\hline \multirow[t]{3}{*}{1} & (Constant) & 41.478 & 6.281 & & 6.604 & .000 \\
\hline & KOMPENSASI & .301 & .060 & .402 & 4.978 & .000 \\
\hline & MOTIVASI & .025 & .105 & .019 & .235 & .814 \\
\hline
\end{tabular}

a. Dependent Variable: KINERJA

Sumber: Data penelitian yang telah diolah dengan IBM SPSS versi 19.

\section{Sumber: Hasil Olah Data Penelitian}

Model Regresi yang diperoleh $Y=41.478+0.301 X_{1}+0.251 X_{2}+e$

1. Konstanta $(\alpha)$ sebesar 41,478 menyatakan bahwa tanpa kompensasi $(x 1)$ dan motivasi (x2) maka besarnya nilai kinerja (y) adalah 41,478

2. Variabel kompensasi $\left(x_{1}\right)$ berpengaruh postif terhadap kinerja $(y)$ dengan nilai koefisiensi sebesar 0,301 , yang artinya jika variabel kompensasi $\left(x_{1}\right)$ meningkat satu satuan dengan asumsi variabel motivasi $\left(\mathrm{x}_{2}\right)$ tetap, maka kinerja (y) akan meningkat sebesar 0,301, sehingga besar nya pengaruh kompensasi $\left(\mathrm{x}_{1}\right)$ terhadap kinerja $(\mathrm{y})$ sebesar $30,1 \%$.

3. Variabel motivasi $\left(x_{2}\right)$ berpengaruh positif terhadap kinerja $(y)$ dengan nilai koefisien sebesar 0,025 yang artinya jika variabel motivasi $\left(\mathrm{x}_{2}\right)$ meningkat satu satuan dengan asumsi variabel kompensasi $\left(\mathrm{x}_{1}\right)$ tetap, maka kinerja $(\mathrm{y})$ akan meningkat sebesar 0,025 . Sehingga besarnya pengaruh motivasi $\left(x_{2}\right)$ terhadap kinerja sebesar 2,50\%.

Koefisiensi determinasi $\left(R^{2}\right)$ bertujuan untuk mengetahui seberapa besar kemampuan variabel independen menjelaskan variabel dependen, dapat dilihat pada tabel berikut ini:

Tabel 1.4

Koefisien Determinasi

\begin{tabular}{|l|r|r|r|c|}
\hline \multicolumn{7}{|c|}{ Model Summary $^{\mathbf{b}}$} \\
Model & $\mathbf{R}$ & R Square & \multicolumn{1}{c|}{$\begin{array}{c}\text { Adjusted R } \\
\text { Square }\end{array}$} & $\begin{array}{c}\text { Std. Error of the } \\
\text { Estimate }\end{array}$ \\
\hline 1 & $.410^{\mathrm{a}}$ & .168 & .157 & 6.117 \\
\hline
\end{tabular}

a. Predictors: MOTIVASI, KOMPENSASI

b. Dependent Variable: KINERJA

\section{Sumber: Hasil Olah Data Primer}

Hasil uji koefisien determinasi dilihat dari nialai ( $R$ Square) yang diperoleh sebesar 0,168. Hal ini berarti 16,8 \% kinerja $(y)$ dipengaruhi oleh variabel kompensasi $\left(\mathrm{x}_{1}\right)$ dan motivasi $\left(\mathrm{x}_{2}\right)$ sedangkan sisanya $83,2 \%$ kinerja $(\mathrm{y})$ dipengaruhi oleh variabel-variabel lain yang tidak diteliti. 


\section{Uji Hipotesis}

\section{a. Uji T}

Untuk mengetahui terdapat pengaruh antara kompensasi $\left(x_{1}\right)$ dan motivasi kerja $\left(\mathrm{x}_{2}\right)$ terhadap kinerja maka perlu dilakukan uji signifikansi dengan menggunakan uji statistik (uji t) dengan menggunakan taraf siginifikansi sebsar 5\% $(0,05)$ dan derajat kebebasan ( $\mathrm{dk}$ ) korelasi dengan rumus: $\mathrm{dk}=\mathrm{n}-\mathrm{k}-1$, dimana $n$ adalah jumlah responden, dan $k$ adalah jumlah variabel yang diteliti. Dimana $t$ tabel diperoleh:

Tabel 1.5

\section{Hasil Uji T}

Coefficients $^{\mathrm{a}}$

\begin{tabular}{|c|c|c|c|c|c|c|}
\hline \multirow[b]{2}{*}{ Mode } & & \multicolumn{2}{|c|}{ Unstandardized Coefficients } & \multirow{2}{*}{$\begin{array}{c}\text { Standardized } \\
\text { Coefficients }\end{array}$} & \multirow[b]{2}{*}{$t$} & \multirow[b]{2}{*}{ Sig. } \\
\hline & & B & Std. Error & & & \\
\hline \multirow[t]{2}{*}{1} & (Constant) & 42.642 & 3.851 & & 11.073 & .000 \\
\hline & KOMPENSASI & .307 & .055 & .410 & 5.543 & .000 \\
\hline
\end{tabular}

a. Dependent Variable: KINERJA

\section{Sumber: Hasil Olah Data Primer}

1) Kompensasi $\left(X_{1}\right)$ terhadap Kinerja $(Y)$

Berdasarkan diatas dapat dilihat bahwa variabel kompensasi $\left(\mathrm{x}_{1}\right)$ diperoleh signifikansi $\mathrm{t}$ lebih kecil dari 0,05 $(0,000<0,05)$ dan $\mathrm{t}$ hitung $5,543>\mathrm{t}$ tabel sebesar 1,975 $(5,543>1,975)$ atau berarti $\mathrm{H}_{01}$ ditolak dan $\mathrm{H}_{\mathrm{a} 1}$ diterima, hal ini menunjukan bahwa terdapat pengaruh yang signifikan dari kompensasi $\left(\mathrm{x}_{1}\right)$ terhadap kinerja $(\mathrm{y})$.

\begin{tabular}{|c|c|c|c|c|c|c|}
\hline \multicolumn{7}{|c|}{ Coefficients $^{a}$} \\
\hline \multirow{2}{*}{\multicolumn{2}{|c|}{ Model }} & \multicolumn{2}{|c|}{$\begin{array}{c}\text { Unstandardized } \\
\text { Coefficients }\end{array}$} & \multirow{2}{*}{$\begin{array}{c}\text { Standardized } \\
\text { Coefficients } \\
\text { Beta }\end{array}$} & \multirow[b]{2}{*}{$\mathbf{t}$} & \multirow[b]{2}{*}{ Sig. } \\
\hline & & B & Std. Error & & & \\
\hline 1 & (Constant) & 49.201 & 6.545 & & 7.517 & .000 \\
\hline & MOTIVASI & .232 & .104 & .179 & 2.240 & .027 \\
\hline
\end{tabular}

a. Dependent Variable: KINERJA

Sumber: Data penelitian yang telah diolah dengan IBM SPSS versi 19

\section{2) Motivasi Kerja $\left(\mathrm{X}_{2}\right)$ terhadap Kinerja ( $\left.\mathrm{Y}\right)$}

Berdasarkan tabel diatas dapat dilihat bahwa variabel motivasi $(\mathrm{x} 2)$ diperoleh signifikansi $\mathrm{t}$ lebih kecil dari 0,05 $(0,027<0,05)$ dan $\mathrm{t}$ hitung 2,240 $>\mathrm{t}$ tabel sebesar 1,975 $(2,240>1,975)$ atau berarti $\mathrm{H}_{02}$ ditolak dan $\mathrm{H}_{\mathrm{a} 2}$ diterima, hal ini menunjukan bahwa terdapat pengaruh yang signifikan dari motivasi $\left(\mathrm{x}_{2}\right)$ terhadap kinerja $(\mathrm{y})$.

\section{b. Uji F}

Untuk menguji pengaruh kompensasi $\left(x_{1}\right)$ dan motivasi $\left(x_{2}\right)$ secara bersamasama terhadap kinerja (y), dapat digunakan uji statistik $F$ (uji $F$ ), dengan menggunakan taraf signifikansi 5\% $(0,05)$. 
Tabel 4.7

Hasil Uji F

ANOVA $^{\text {b }}$

\begin{tabular}{|ll|r|r|r|c|c|}
\hline Model & & Sum of Squares & df & Mean Square & F & Sig. \\
\hline 1 & Regression & 1144.622 & 2 & 572.311 & 15.293 & $.0000^{\mathbf{a}}$ \\
& Residual & 5650.917 & 151 & 37.423 & & \\
& Total & 6795.539 & 153 & & & \\
\hline
\end{tabular}

a. Predictors: (Constant), MOTIVASI, KOMPENSASI

b. Dependent Variable: KINERJA

Sumber: Data penelitian yang telah diolah dengan IBM SPSS versi 19.

\section{Sumber: Hasil Olah Data Primer}

Dari hasi uji $F$ dapat diperoelh nilai $f_{\text {nitung }}>f_{\text {tabel }}$ yaitu 15,293 $>3,06$ dan nilai sig $<0,05$ atau 0,000 $<0,005$ "Maka, kompensasi dan motivasi memiliki pengaruh yang signifikan terhadap kinerja"

\section{G. Analisis Hasil Penelitian dan Pembahasan}

\section{Kompensasi}

a. Dari hasil uji validitas dan reliabilitas maka instrument kuisioner menunjukan valid seperti instirumen kuisioner no $1(0,473>0,361)$ dan begitupun hasil uji reliabilitas kuisioner dimana nilai $r_{\text {ca }}(0,931)>$ tabel $(0,361)$ dinyatakan reliabel.

b. Dari hasil uji analisis regresi berganda maka diperoleh nilai koefisien 0,301, sehingga besar nya pengaruh Kompensasi $\left(x_{1}\right)$ terhadap kepuasan pelanggan (y) sebesar $30,1 \%$.

c. Dan hasil uji hipotesis maka diperoleh nilai $\mathrm{t}_{\text {hitung }} 5,543>\mathrm{t}$ tabel sebesar $1,975(5,54>1,975)$ atau berarti $\mathrm{H}_{01}$ ditolak dan $\mathrm{H}_{\mathrm{a} 1}$ diterima, hal ini menunjukan bahwa terdapat pengaruh yang signifikan dari kompensasi $\left(\mathrm{x}_{1}\right)$

\section{Motivasi Kerja} terhadap kinerja (y).

a. Dari hasil uji validitas dan reliabilitas maka instrument kuisioner menunjukan valid seperti instirumen kuisioner no $1(0,497>0,361)$ dan begitupun hasil uji reliabilitas kuisioner dimana nilai $r$ ca $(0,853)>$ tabel $(0,361)$ dinyatakan reliabel.

b. Dari hasil uji analisis regresi berganda maka diperoleh nilai koefisien 0,025, sehingga besar nya pengaruh motivasi kerja $\left(x_{2}\right)$ terhadap kinerja $(y)$ sebesar $2,50 \%$.

c. Dan hasil uji hipotesis maka diperoleh variabel motivasi (x2) diperoleh signifikansi $\mathrm{t}$ lebih kecil dari 0,05 $(0,027<0,05)$ dan $\mathrm{t}$ hitung $2,240>\mathrm{t}$ tabel sebesar 1,975 $(2,240>1,975)$ atau berarti $\mathrm{H}_{02}$ ditolak dan $\mathrm{H}_{\mathrm{a} 2}$ diterima, hal ini menunjukan bahwa terdapat pengaruh yang signifikan dari motivasi $\left(\mathrm{x}_{2}\right)$ terhadap kinerja $(\mathrm{y})$

3. Kinerja

a. Dari hasil uji validitas dan reliabilitas maka instrument kuisioner menunjukan valid seperti instirumen kuisioner no $1(0,671>0,361)$ dan begitupun hasil uji reliabilitas kuisioner dimana nilai $r$ ca $(0,874)>$ tabel $(0,361)$ dinyatakan reliabel. 
b. Dari hasil uji koefisien determinasi dilihat dari nialai ( $R$ Square) yang diperoleh sebesar 0,168. Hal ini berarti 16,8 \% kinerja (y) dipengaruhi oleh variabel kompensasi $\left(x_{1}\right)$ dan motivasi $\left(x_{2}\right)$ sedangkan sisanya 83,2\% kinerja $(y)$ dipengaruhi oleh variabel-variabel lain yang tidak diteliti.

\section{H. Kesimpulan}

1. Kompensasi $\left(\mathrm{X}_{1}\right)$ dalam penelitian ini mempunyai pengaruh positif dan signifikan terhadap kinerja karyawan, sehingga hipotesis yang diajukan "diduga terdapat pengaruh positif dan signifikan kompensasi terhadap kinerja karyawan" telah terbukti. Nilai koefesien korelasi $(R)$ didapat sebesar 0,410 menunjukkan pengaruh cukup kuat, sedangkan koefisien determinasi kompensasi $\left(X_{1}\right)$ terhadap kinerja karyawan $(\mathrm{Y})$ diperoleh $R$ Square $\left(R^{2}\right)=0,168$ ini berarti bahwa kompensasi $\left(\mathrm{X}_{1}\right)$ berpengaruh sebesar $16,8 \%$ terhadap kinerja $(Y)$.

2. Motivasi kerja $\left(\mathrm{X}_{2}\right)$ mempunyai pengaruh positif dan signifikan terhadap kinerja karyawan $(\mathrm{Y})$ sehingga hipotesis yang diajukan "diduga terdapat pengaruh positif dan signifikan motivasi kerja terhadap kinerja karyawan" telah terbukti. Nilai koefesien korelasi $(R)$ didapat sebesar 0,179 menunjukkan pengaruh sangat lemah, sedangkan koefisien determinasi pengaruh motivasi kerja $\left(\mathrm{X}_{2}\right)$ dengan kinerja karyawan $(\mathrm{Y})$ diperoleh $R$ Square $\left(R^{2}\right)=0,032$ ini berarti bahwa motivasi kerja $\left(\mathrm{X}_{2}\right)$ berpengaruh sebesar $3,2 \%$ terhadap kinerja $(\mathrm{Y})$.

3. Kompensasi $\left(X_{1}\right)$ dan Motivasi kerja $\left(X_{2}\right)$ secara bersama-sama mempunyai pengaruh positif dan signifikan terhadap kinerja karyawan $(\mathrm{Y})$, sehingga hipotesis yang diajukan "diduga terdapat pengaruh positif dan signifikan secara bersamasama antara kompensasi dan Motivasi kerja terhadap kinerja karyawan ", telah terbukti. Nilai koefesien korelasi $(R)$ didapat sebesar 0,410 menunjukkan pengaruh cukup kuat, sedangkan koefisien determinasi kompensasi $\left(\mathrm{X}_{1}\right)$ dan Motivasi kerja $\left(\mathrm{X}_{2}\right)$ secara simultan terhadap karyawan $(\mathrm{Y})$ diperoleh $R$ Square $\left(R^{2}\right)=0,168$ ini berarti bahwa kompensasi $\left(X_{1}\right)$ dan motivasi kerja $\left(X_{2}\right)$ secara bersama-sama berpengaruh sebesar $16,8 \%$ terhadap kinerja $(\mathrm{Y})$.

\section{Daftar Pustaka}

Adi,Rukminto, Isbandi, 1994, Psikolog Pekerjaan Sosial \& IImu Kesejahteraan, RajaGrafindo Persada, Jakarta.

Arikunto,Suharsimi,2004,Prosedur Penelitiansuatu Pendekatan Praktek, Rinekacipta,Jakarta.

Bangun, Wilson, 2012, Manajemen Sumber Daya Manusia, Erlangga, Jakarta.

Brantas, 2009, Dasar-dasar Manajemen, Alfabeta, Bandung.

Cardoso, G.F, 2003, Manajemen Sumber Daya Manusia, Andi Offset, Yogyakarta.

Dessler, Gary, 1997, Manajemen Sumber Daya Manusia, Jilid 1,Prenhallindo, Jakarta. -, 1997, Manajemen Sumber Daya Manusia, Jilid 2, Prenhallindo, Jakarta.

Fahmi, Irham, 2011, Manajemen Pengambilan Keputusan, Alfabeta, Bandung.

G.R. Terry danL.W.Rue, 2009, Dasar-Dasar Manajemen, Bumi Aksara, Jakarta.

Ghozali, Imam, 2007; 2011,Aplikasi Analisis Multivariate Dengan Program SPSS, BP Universitas Diponogoro, Semarang.

Handoko, T. Hani, 1994, Manajemen Personalia dan Sumberdaya Manusia, Edisi 2, BPFE, Yogyakarta.

Hasibuan, Malayu, S.P, 2011, Manajemen Sumber Daya Manusia, Bumi Aksara, Bandung.

Bandung, 2009

Ibnu, Hajar, 1999, Dasar-dasar Penelitian Kwalitatif dalam Pendidikan, RajaGrafindo Persada, Jakarta.

Lautan Otsuka Chemical, 2013, Perjanjian Kerja Bersama (PKB), Cilegon.Perusahaan. 
Jakarta: Raja Grafindo Persada.

L. Mathis, Robert dan Jhon H, Jackson, 2009, Manajemen Sumber Daya Manusia,Edisi 10, Salemba Empat, Jakarta.

Mangkunegara, Prabu, Anwar, 2006, Evaluasi Kinerja SDM, Refika Aditama, Bandung.

Perusahaan,Remaja Rosdakarya,Bandung.

2001, Manajemen Sumber Daya Manusia

Martoyo,2007, Manajemen Sumber Daya Manusia, BPFE, Yogyakarta.

Moeheriono, 2012, Indikator Kinerja Utama (IKU), RajawaliPers, Jakarta.

-, 2012, Indikator Kinerja Utama, RajaGrafindoPersada, Jakarta.

Munandar, 2001, Psikologi Industri dan Organisasi, UI Pers, Jakarta.

Murdiyah Hayati, Suhendra, 2006, Manajemen Sumber Daya Manusia, UIN Jakarta Press, Jakarta.

Notoatmojo, Soekidjo, 2009, Pengembangan Sumberdaya Manusia,RinekaCipta, Jakarta.

Prawirosentono, Suyadi, 1999, Kebijakan Kinerja Karyawan, BPFE, Yogyakarta.

Purwanto, Ngalim, M,1990, Psikologi Pendidikan, Remaja Karya, Bandung.

Rianse, Usman dan Abdi SP, 2008, Metodologi Penelitian Sosial dan Ekonomi, Alfabeta, Bandung.

Rivai, Veithzal, 2013, Manajemen Sumber DayaManusia Untuk Perusahaan, RajaGrafindoPersada, Jakarta.

Robbins, Stephen P, 2008, Perilaku Organisasi, Edisi Lengkap, Indeks, Jakarta.

Robbin, Stephen P, Timothy A, Judge, 2008, Perilaku Organisasi, Salemba Empat, Jakarta.

Santoso, Purbayu Budi, Ashari, 2005, Analisis statistic dengan Microsoft exel dan SPSS, Andi Offset, Yogyakarta.

Sardiman, 2006, Interaksi \& Motivasi Belajar Mengajar, Grafindo Persada, Jakarta.

Sedarmayanti, 2011, Manajemen Sumber Daya Manusia, Refika Aditama, Bandung.

Setyosari, Punaji, 2010, Metode Penelitian Pendidikan dan Pengembangan, KencanaPrenada Media Group, Jakarta.

Siagian P.Sondang, 2011, Manajemen Sumber Daya Manusia, Cetakan 9,Bumi Aksara, Jakarta.

Singarimbun, Masri, dan Efendy, 2007, Metode Penelitian Survei, LP3ES, Jakarta.

Sugiyono,2005, Metode Penelitian Administrasi, Alfabeta, Bandung.

----------, 2008, Metodologi Penelitian Kuantitatif Kualitatif dan R\&D, Alfabeta, Bandung.

-------, 2012, Metode Penelitian Bisnis, Alfabeta, Bandung.

Sutrisno, Edy, 2014, Manajemen Sumber Daya Manusia, Kencana Prenada Media Group, Jakarta.

Uno, Hamzah B, 2006, Teori Motivasi dan Pengukurannya, BumiAksara, Jakarta.

Wibowo, 2012, Manajemen Kinerja, RajaGrafindo Persada, Jakarta.

Yamin, Martinis, 2007, Sertifikasi Keguruan di Indonesia,Gaung Persada Press, Jakarta.

Website:

Ali,Muhammad,Manajemen,

http://www.academia.edu/4590898, diunduh tanggal 25 Desember 2014.

Antariksa, Yodia, Menyusun Sistem Performance Appraisal yang Baik,

http://www.manajemen kinerja.com, diunduh tanggal 23 April 2013.

Dharyanti, Amphe, Manajemen, http://ikanteri89.blogspot.com/2014/10/makalah-manajemen-pengertian-fungsidan.html, diunduh tanggal 25 Desember 2014.

Rahmat, Motivasi Kerja, http://www.motivasi-islami.com/motivasi-kerja,diunduh tanggal 05 Oktober 2014.

Sumarsih,ManajemenSumberDayaManusia(MSDM),

http://staff.uny.ac.id/sites/default/files/pengabdian/dra-sumarsih/manajemensdm.pdf, diunduh tanggal 06 Juli 2014. 